DOI 10.37882/2223-2982.2020.12-3.16

\title{
РОЛЬ ВНУТРЕННЕЙ ФОРМЫ АНГЛИЙСКИХ ЗООСЕМИЧЕСКИХ ФРАЗЕОЛОГИЧЕСКИХ ЕДИНИЦ В ОТОБРАЖЕНИИ КУЛЬТУРНОГО ОПЫТА ЯЗЫКОВОГО КОЛЛЕКТИВА
}

\section{THE INNER FORM OF ANIMAL ENGLISH PHRASEOLOGICAL UNITS AS A MIRROR OF THE CULTURAL EXPERIENCE OF SPEECH COMMUNITY}

\section{O. Novikova}

Summary: The goal of the current work is to study the inner form of animal phraseological units which reflect the long process of the English culture development. The in-depth analysis of 315 English metaphors. proverbs and sayings with fauna images showed that the figurative content of the units in question is the mirror of the cultural and national worldview. Special attention is paid to the etymological meaning of fixed word combinations with erased inner form. The focus on the idiomatic phrase origin allows us both to identify the creative thinking peculiarities of the English-speaking people and to reveal the expressiveness of the language units under consideration. The relevance of the research is due to the need to study zoonym images, which are a valuable linguistic heritage, since they embody cultural and historical worldview of the people, their culture, customs and traditions.

Keywords: cultural linguistics, etymology, imagery, English animal phraseological units, zoonym, inner form.

\author{
Новикова Ольга Вячеславовна \\ К.филол.н., дочент, Московский авиационный институт \\ Novikova_English@mail.ru
}

Аннотация: Целью работы является лингвокультурологическое исследование внутренней формы зоосемических фразеологических единиц, которые отражают в своей семантике длительный процесс развития культуры англоязычного народа. Анализ 315 английских метафор, пословиц и поговорок с образами животного мира показал, что в образном содержании исследуемых единиц воплощено культурно-национальное мировидение. Особое внимание уделено рассмотрению этимологического значения устойчивых словесных комплексов со стертой внутренней формой, что позволяет не только выявить своеобразие творческого мышления англоязычного народа, но и эксплицировать экспрессивный потенциал анализируемых языковых единиц. Актуальность исследования обусловлена необходимостью изучения зоонимных образов, которые представляют собой ценное лингвистическое наследие, поскольку в них отображается культурно-историческое мировоззрение народа, его культура, обычаи и традиции.

Ключевые слова: лингвокультурология, этимология, образность, английские зоосемические фразеологические единицы, зооним, внутренняя форма.

но антропологической парадигмы науки о человеке, центром притяжения которой является феномен культуры.

Одним из надежных и эффективных способов изучения английской культуры является фразеологический фонд английского языка, неотъемлемую часть которого составляет активно функционирующий пласт зоосемических фразеологических единиц (ЗФЕ), т.е. устойчивые словосочетания с компонентом-зоонимом, в которых частичная или полная переосмысленность значения их компонентов создает образность.

За последнее десятилетие национальная специфика фразеологизмов с компонентом-зоонимом рассматривалась на материале русского [2], финского [3] и румынского [4], бурятского [5] языков. В фокусе отдельных лингвистов исследования ЗФЕ в семантико-типологическом аспекте на материале английского и русского языков [6], татарского и английского [7], немецкого и английского [8], русского и французского [9], русского и корейского [10], китайского и русского языков [11]. В ряде работ уделяется внимание зоонимам в русской, английской и 
итальянской лингвокультурах [12], проводится сопоставительный анализ национально-культурной специфики ЗФЕ русского, английского, татарского и таджикского языков [13], а также испанского, узбекского, английского и русского языков [14].

Анализ работ, затрагивающих эту тематическую группу в различных ракурсах, повлиял на наш выбор предмета исследования, целью которого является изучение культурного опыта языкового коллектива сквозь призму внутренней формы английских метафорических фразеологических единиц, а также пословиц и поговорок, включающих названия животных.

В качестве объекта исследования методом сплошной Выборки были проанализированы 315 английских ЗФЕ с наиболее частотными стержневыми компонентами badger, bear, bird, bull, cat, dog (hound), fish, fox, goose, horse ox, lion, pheasant, pig, sheep, которые зафиксированы в современных лексико-фразеологических источниках [15; $16 ; 17 ; 18 ; 19 ; 20]$.

Актуальность работы обусловлена повышенным вниманием лингвистов к исследованию ЗФЕ, которые являются древнейшей частью фразеологического фонда английского языка, что позволяет определить национально-специфичные черты их семантики.

Новизна предпринятого исследования заключается в выделении и комплексном исследовании английских ЗФЕ, которые играют особую роль в трансляции национально-культурного самосознания народа и его идентификации.

Теоретическое значение работы определяется возможностью дальнейшего развития семантической концепции фразеологической образности и выявления общих принципов создания образности ЗФЕ в аспекте лингвокогнитивного представления ментального мира человека.

Практическая ценность исследования заключается в прикладном использовании результатов и материалов при разработке курсов и проведении спецсеминаров по лингвострановедению, общему языкознанию и лингвокультурологии современного английского языка.

Исследование языкового материала с помощью таких методов лингвистического анализа, как компонентный, денотативный, лексико-семантический анализ, описательный, лингвокультурологический анализ, анализ словарных дефиниций свидетельствует о том, что отображение культурного опыта языкового коллектива осуществляется через образные представления, лежащие в основе ЗФЕ.
Наблюдения людей за повадками представителей животного мира послужили причиной появления переносно образных символических значений слов, на их основе - ЗФЕ, в которых поведение человека отождествляется с поведением этих животных.

Образность значения ЗФЕ предполагает обязательное наличие внутренней формы. Понятие внутренней формы (ВФ), зародившееся в трудах В. фон Гумбольдта, прочно вошло в обиход лингвистов. В. фон Гумбольдт выдвинул идею о том, что человек переносит в язык то, что его «живо волнует» [21. с. 401], т.е. вкладывает в название предмета или явления те или иные признаки, осмысленные называющим и представляющие для него значимость. Разные понятия порождаются фантазией и чувствами, отражающими индивидуальный характер нации, и являются разными внутренними формами обозначений.

Большая заслуга в разработке проблемы ВФ применительно к языковому материалу принадлежит русскому ученому А.А. Потебне, давшему несколько определений ВФ, одно из которых указывает, что ВФ - это «ближайшее этимологическое значение» языковых единиц [22, с. 83-84]. Наиболее последовательным представляется также определение ВФ ФЕ, разработанное А.В. Куниным как «значение ее прототипа, с которым фразеоматическое значение связано деривационными отношениями» $[23$, с. 173].

По степени участия ВФ ЗФЕ в наименовании явлений объективной действительности различают живую и стертую ВФ. Под живой ВФ ЗФЕ мы понимаем те признаки образности, которые понятны носителю языка, осознаются им и вызывают у него прямую ассоциативную связь со значением переменного прототипа. К этому разряду относится, например, ЗФЕ to take the bull by the horns 'действовать решительно, мужественно преодолевать затруднения'. Для носителей языка данная ЗФЕ ассоциируется с крайней степенью мужества. Таким образом, ВФ ЗФЕ 'взять быка за рога' воспринимается как компонент ее значения.

ЗФЕ не всегда обладают ясной внутренней формой, часто их образ завуалирован. Целый ряд ЗФЕ содержит В своей семантике национально-культурный компонент - или синхронно, с позиции современного языкового сознания, или диахронно, т.е. только по причине сопряженности с национальной культурой словосочетанияпрототипа [24, с. 70-71].

Следует подчеркнуть, что наиболее значимы с точки зрения изучения культуры англоязычного народа являются ЗФЕ со стертой ВФ. Стертая ВФ означает наличие таких мотивирующих признаков, для оживления которых требуется развернутое этимологическое исследование 
с привлечением объяснений и другой дополнительной информации. Значение подобных ЗФЕ может быть восстановлено в отдельных элементах толкования фразеологических источников: авторских комментариях и пояснениях и практически не восстанавливается в речи.

Для уточнения словарных данных были проанализированы словарные статьи этимологических и толковых словарей $[25 ; 26 ; 27]$. Например, ВФ ЗФЕ go the whole hog со значением 'достичь цели, делать что-л. основательно, доводить что-л. до конца', оказывается не до конца понятной. Этимология выражения восполняет этот недостаток. Слово hog 'боров' первоначально означало сленг для названия монеты shilling, поэтому to go the whole hog означало 'потратить весь шиллинг сразу же'.

Знание этимологии ЗФЕ со стертой ВФ ЗФЕ no room to swing a cat 'очень тесно, повернуться негде' способствует экспликации ее экспрессивного потенциала ВФ'не было места для кошки', которая в гиперболической форме обычно описывает мероприятие, на котором много народу. Первоначально фраза имела вид not room to swing a cat-o'nine-tails - не было места, чтобы хлестнуть «кошкойдевятихвосткой» ЗФЕ датируется временем, когда моряков пороли на борту корабля «кошкой-девятихвосткой», плетью из девяти ремней, расходящихся на конце. До 1881 года подобная процедура побоев происходила на палубе и официально применялась для наказания в английской армии и на флоте. Каюты были настолько малы, что нельзя было повернуться даже кошке.

Через восстановление ВФ появляется возможность выделения экспрессивности в структуре содержания и ЗФЕ the Trojan horse. Рассматриваемое выражение означает дары, поднесенные с предательским умыслом. Они таят в себе опасность или гибель для тех, кому они предназначены. История этого выражения такова. Долго и безуспешно вели греки (данайцы) осаду Трои. В конце концов, они решили прибегнуть к военной хитрости, соорудив огромного деревянного коня - будто бы в знак окончания войны. Греки оставили деревянного коня у стен Трои, а сами сделали вид, что возвращаются домой. Троянцы, движимые любопытством, втащили коня в свой город. Ночью воины-данайцы, спрятавшиеся внутри деревянного коня, вышли и ворвались в Трою. Троя была захвачена и разрушена.

Экстралингвистическая база зоонимов довольно разнообразна: «причины неадекватных коннотаций следует искать вне языка - в системе ценностей, обычаев, традиций конкретной лингвокультурной общности» [1, с. 24].

Рыболовство, как одна из ведущих отраслей хозяйства Англии и США, послужило источником возникновения многих пословичных ЗФЕ, тематическим индикатором которых является зооним fish: catch fish with a silver hook - 'покупать рыбу после неудачной рыбной ловли'; all is fish that comes to his net - 'доброму вору все впору, он все использует, он из всего извлекает выгоду'; he who would catch fish must not mind getting wet - 'без труда не вытащишь и рыбки из пруда'; if you swear you will catch no fish - 'руганью делу не поможешь'; it is a silly fish, that is caught twice with the same bait - 'глуп тот, кто два раза попадается на одну и ту же удочку'; never fry a fish till it's caught - 'не радуйся раньше времени, цыплят по осени считают, не убив медведя, шкуры не продавай'; venture a small fish to catch a great one -'стоит рискнуть малым ради большего'.

Анализ внутренней формы 315 3ФЕ показал, что $78 \%$ метафорических 3ФЕ и 22 \% пословиц и поговорок с образами животного мира вербализуют также такие виды деятельности человека, как охота, скачки, военное дело, крестьянский труд и игры. Приведем ряд примеров, иллюстрирующих обозначенные сферы деятельности человека:

- Охота на животных: to ride past the hounds -'опережать события, забегать вперед (проезжать мимо охотничьих собак)'; to follow the hounds - 'следовать привычке, наклонностям (следовать за гончими)'; to hound a dog on somebody - 'подстрекать кого- либо (натравливать собаку на кого-л.)'; to call off the dogs - 'переменить неприятную тему разговора' (охотники отзывали собак, когда они теряли след); dog in a doublet - 'смелый, отважный парень' (охотники надевали на охотничьих собак кожаные камзолы, которые предохраняли их во время охоты на кабана); to draw the badger - 'заставить кого-либо проговориться' (вытаскивать барсука); loaded for a bear - 'злой, готовый к драке, пьяный' (ЗФЕ этимологически связана с охотой на медведя, по ассоциации с особой подготовкой охотников к охоте на медведя); stalking-horse - 'предлог, отговорка (заслонная лошадь)'.

- Охота на птиц: sitting duck - 'легкая добыча, удобная мишень (сидящая утка)'; to shoot the sitting pheasant - 'погубить, испортить репутацию человека (стрелять в сидящего фазана)'.

- Военное дело: war horse -'пьеса, опера, симфония, потерявшая оригинальность в результате многократной постановки, исполнения (военная лошадь)'; to be on the high - horse - 'важничать, высокомерно держаться' (выражение возникло в связи с тем, что феодалы, обыкновенно сражавшиеся верхом, презрительно относились к пехоте, состоявшей из наемников и простолюдинов); to ride the fore-horse - 'быть впереди, играть главную роль'.

- Скачки: ask a horse the question - 'добиваться от лошади напряжения всех ее сил во время бегов (задавать лошади вопросы)'; dark horse - 'малоизвестный кандидат на выборах (темная лошадка)'; talk horse - 'хвастаться (говорить о лошадях)'; to back 
the wrong horse - 'сделать плохой выбор, просчитаться, ошибиться в расчетах (поставить не на ту лошадь)', to flog a willing horse - 'подгонять добросовестного работника (стегать добросовестную лошадь)'.

- Крестьянский труд: off ox - 'неуклюжий, неповоротливый человек' (бык, занимающий место в правой стороне упряжки, поэтому находящийся вне поле зрения извозчика; при движении животному трудно было удерживать равновесие); not to know one from the Adam's off ox - 'не иметь ни малейшего представления о человеке, о котором идет речь'.

- Игры: fox and hounds - 'лиса и собаки' (детская игра, где один ребенок бежит, а остальные его ловят); to play ducks and drakes with: - 1) 'бросать плоские камешки по поверхности воды'; 2) 'разбазаривать, растрачивать попусту что-либо, рисковать'; fox and geese - 'лиса и гуси', 'волки и овцы' (род игры в шашки, в которой у одного игрока одна дамка, а у другого - четыре); cat and mouse game - 'игра в кошки - мышки'; wild-goose chase 'скачки на лошадях гуськом'; 'сумасбродная затея' является прототипом названия игры, известной в шекспировские времена, в которой принимали участие несколько всадников. Всадник, одержавший победу, был впереди, а все остальные на определенном расстоянии за ним. Это название игры этимологически связано с полетом диких гусей; the hobby-horse is forgotten - 'конек-скакунок забыт, об этом уже забыли' - этимологически связана с английскими народными гуляниями, представлениями, во время которых актеры на потеху публике скакали на деревянных лошадках; horse play - 'прыгать, паясничать, шумная игра, грубое развлечение'.

Приведенные примеры, в основе которых лежит остаточное представление о каком-либо факте, явлении, событии, подтверждают идею В. фон Гумбольдта о том, что во внутренней форме отражен дух народа, а различные языки - это различные видения одного и того же предмета [21, с. 100-105].

Конкретную экстралингвистическую направленность имеют ЗФЕ, генетически свободные словосочетания которых описывали предания, народные поверия: to take a hair of the dog that bit you, to lead apes in hell, swan song, басни, легенды: kill the goose that lays the golden eggs, to bell the cat, wolf in sheep's clothing, crocodile tears, lion's share, black ox, to make a cat's paw of smb.

Приведем несколько примеров, демонстрирующих своеобразие мышления англоязычного народа:

- to lead apes in hell - 'умереть старой девой' - связана с английским поверьем о том, что старым девам суждено после смерти нянчить обезьян в аду;
- to bell the cat - 'отважиться, взять на себя риск, инициативу в опасном деле, рискованном предприятии' связана с басней, которая гласит о том, что однажды мыши договорились повесить колокольчик на шею кошки, чтобы знать о ее приближении. Однако никто из мышей не осмелился это сделать;

- white elephant - 'обременительное или разорительное имущество, подарок, от которого не знаешь, как избавиться, обуза'. Происхождение связано с легендой о том, что король Сиама, желая разорить кого-либо из своих подданных, дарил ему священного белого слона, содержание которого обходилось очень дорого;

- halcyon days - 'спокойные, мирные дни, спокойное время'. По древнему преданию, зимородок выводит птенцов в гнезде, плавающем по морю, в период зимнего солнцестояния, и в этот период, около двух недель, море бывает совершенно спокойным;

- lion's share - ЗФЕ 'львиная доля' употребляется для обозначения большей, лучшей доли чего-либо, которую при дележе берет сильнейший. Выражение заимствовано из басни древнегреческого баснописца Эзопа о льве, который с помощью других зверей поймал оленя и угрозами заставил зверей отдать ему всю добычу.

Анализ языкового материала, в качестве которого послужили 315 ЗФЕ, позволил сделать вывод о том, что ЗФЕ отражают народную культуру своими прототипами - свободными словосочетаниями, описывающими определенные обычаи, праздники, легенды, подробности быта и многое другое.

Культурная информация хранится во внутренней форме, которая, являясь образным представлением о мире, придает ЗФЕ культурно-национальный колорит. Образное восприятие окружающей действительности находит свое воплощение в образах метафорического происхождения, в которых видится ключ к пониманию основ мышления и процессов создания национальноспецифического видения мира.

Комплексный анализ ЗФЕ позволил выявить лингвокультурологические особенности метафор со стертой ВФ, которые несут на себе отпечаток духовной и материальной культуры английского языка, что прослеживается в вербальном отражении таких сфер деятельности, как охота, скачки, рыболовство, военное дело и крестьянский труд. Внутренняя форма пословиц и поговорок с компонентами-зоонимами формирует оценочную картину мира, где образно запечатлен опыт нации в ходе исторического развития.

Актуальность работы обусловлена перспективно- 
стью дальнейшего изучения зоонимных образов, поскольку устойчивые словесные комплексы с названиями представителей животного мира, воспроизводимые из поколения в поколение, составляют обширный пласт любого языка и являются самой распространенной и древней формой языковой номинации.

Правильное использование зоосемической фразеологии необходимо для успешного овладения межкультурной коммуникацией.

\section{ЛИТЕРАТУРА}

1. Мамонтов А.С. Язык и культура: основы сопоставительного лингвострановедения: Автореф. дис. ... д-ра филол. наук. - М., 2000. - 53 с.

2. Огдонова Ц.Ц. Зооморфная лексика как фрагмент русской языковой картины мира: Дис. . . . канд. филол. наук. - Иркутск, 2000. - 162 с.

3. Соколова М.В. Семантические характеристики анималистических фразеологизмов финского языка. Вестник Марийского государственного университета. - 2012. - № 8. - С. $92-94$.

4. Кубасова А.0. Образная характеристика человека в румынском языке через сравнения с животными и зоометафоры: лексико-семантический анализ. Дис. ... канд. филол. наук. - СПб., 2008. - 173 с.

5. Дондокова Н.П. Зоосемические фразеологические единицы бурятского языка: Структура, семантика, функции. Автореф. .... дис. канд. филол. наук. Улан-Удэ, 2008. -24 с.

6. Богоявленская Ю.В., Симонова Е.С. Сопоставительный анализ национально-культурной специфики эмотивных фразеологических единиц с компонентом-зоонимом в английском и русском языках. Многоязычие в образовательном пространстве. - 2018. - № 10. - С. $75-82$.

7. Ганиева Э.С., Исмаилова С.А. Фразеологические единицы с компонентом-зоонимом в крымскотатарском и английском языках: лингвокультурологический аспект. Вопросы крымскотатарской филологии, истории и культуры. - 2016. - № 3. - С. 25-29.

8. Лаврищева Е.В., Аброськина Н.Б., Остроухова А.В. Национальная специфика фразеологизмов с компонентом-зоонимом в немецкой и английской языковой картине мира. Вестник Волжского университета им. В.Н. Татищева. -2019. - № 2 (2). - С. 40-46.

9. Пучков В.О. Репрезентация внешних качеств человека в русских и французских фразеологизмах с компонентом-зоонимом. Вестник Волгоградского государственного университета. Серия 2: Языкознание. - 2015 - №4. - С. 47-55.

10. Антонова А.Б., Ким Чжиён. The structural-semantic peculiarities of animalistic phraseologisms describing a human's appearance and character in Russian and Korean. Crede Experto: транспорт, общество, образование, язык. - 2017. - №3. - С. 87-93.

11. Донова 0.В. Сопоставление символов в культурной семантике фразеологизмов китайского и русского языков. Мир науки, культуры, образования .2009. - №3. - С. 78-82.

12. Куличенко Ю.Н., Королевская Е.М. Сопоставительный анализ фразеологических единиц с компонентом-зоонимом. Научный диалог. - № 4. - 2017. C. 44-56.

13. Сакаева Л.Р. Характерные особенности использования компонентов-зоонимов во фразеологизмах, пословицах и поговорках русского, английского, татарского и таджикского языков. Вестник Санкт-Петербургского университета. Язык и литература. - 2009. - № 1-2. - С. 140 - 144.

14. Бахронова Д.К. Лингвокультурные особенности зооморфных фразеологических единиц. Вестник Челябинского государственного университета. - 2016. - № 9 (391), - С. 36-43.

15. Кунин А.В. Большой англо-русский фразеологический словарь/ 4-е изд., перераб. и доп. - М.: Русский язык, 1984. - 944 с.

16. Cambridge Dictionary. - URL: http://dictionary.cambridge.org/

17. Macmillan Dictionary. - URL: http://www.macmillandictionary.com/

18. The 0xford English Dictionary. - URL: http://oxforddictionaries.com

19. Longman Dictionary of English Language and Culture. - Harlow: Longman, 2005. - 1621 p.

20. Apperson G.L. The Wordsworth Dictionary of Proverbs. - London: Wordsworth Reference, 2006. -656 p.

21. Гумбольдт В. фон. Избранные труды по языкознанию. - М.: Прогресс, 1984. - 398 с.

22. Потебня А.А. Мысль и язык. - Харьков, 1926. - 130 с.

23. Кунин А.В. Курс фразеологии современного английского языка. - М.: Высшая школа, 1996. - 381с.

24. Верещагин Е.М. Костомаров В.Г. Язык и культура: Лингвострановедение в преподавании русского языка как иностранного. - М.: Русский язык, 1990. - 246 с.

25. Collins Dictionary - URL: https://www.collinsdictionary.com/dictionary/english-thesaurus

26. Cambridge Advanced Learner's Dictionary. URL: http://dictionary.cambridge.org/dictionary/british/.

27. Multitran Dictionary - URL: https://www.multitran.com/

(с) Новикова Ольга Вячеславовна (Novikova_English@mail.ru).

Журнал «Современная наука: актуальные проблемы теории и практики» 